\title{
Retention in HIV care and associated factors among youths aged $15-24$ years in rural southwestern Uganda
}

Moses Muwanguzi ${ }^{1}$, Henry Mark Lugobe ${ }^{1,2}$, Elastus Ssemwanga ${ }^{1}$, Allan Phillip Lule ${ }^{1}$, Elizabeth Atwiine', Vincent Kirabira', Ann K. Stella', Scholastic Ashaba ${ }^{1,3}$ and Godfrey Zari Rukundo ${ }^{1,3^{*}}$ (D)

\begin{abstract}
Background: Retention in HIV care contributes to antiretroviral therapy adherence, which is a key factor for improved treatment outcomes and prevention of drug resistance. However, HIV treatment among the youths is characterized by loss to follow up, poor adherence to ART, risk of treatment failure and high mortality rates compared to young children and adults. There is limited information about factors associated with retention of youths in HIV care in rural settings in Uganda. We aimed to determine retention in HIV care and associated factors among youths aged 15-24 years in rural southwestern Uganda.

Methods: A cross-sectional study was conducted among youths aged 15-24 years who were receiving care at the HIV clinic at Kabuyanda HC IV who had been in care for at least 1 year before the study. We used an intervieweradministered questionnaire to collect socio-demographic information. Participant chart abstraction was used to collect information on HIV clinic attendance. We collected information on HIV related stigma using the 40-item Berger Stigma Scale. Chi-square test and multivariable logistic regression analysis were used to determine the factors associated with retention in HIV care with a significance level of $<0.05$. Retention in HIV care was, defined as having sought care at least once per quarter in the 12 months prior to the study.

Results: We enrolled 102 participants with a mean age of 20.95 (SD \pm 3.07 ) years. Two thirds (65.7\%) of the youths had been retained in HIV care in the previous 12 months. In adjusted analyses, being male, married and had perinatally acquired HIV were independently associated with retention in HIV care. The association between HIV related stigma and retention in HIV care was not statistically significant.

Conclusion: Retaining adolescents and young adults in HIV care in rural southwestern Uganda is still much lower than the WHO target of 90\%. Being male, having perinatally acquired HIV and married or in a relationship are associated with retention in HIV care. Interventions targeting adolescents and young adults living with HIV are necessary to improve retention in HIV care to the WHO target of 90\%.
\end{abstract}

Keywords: HIV/AIDS, HIV stigma, Retention in HIV care, Youths, ART

\footnotetext{
* Correspondence: grukundo@must.ac.ug

'Mbarara University of Science and Technology, Faculty of Medicine,

Mbarara, Uganda

${ }^{3}$ Department of Psychiatry, Mbarara University of Science and Technology,

Mbarara, Uganda

Full list of author information is available at the end of the article
}

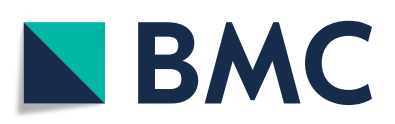

(c) The Author(s). 2021 Open Access This article is licensed under a Creative Commons Attribution 4.0 International License, which permits use, sharing, adaptation, distribution and reproduction in any medium or format, as long as you give appropriate credit to the original author(s) and the source, provide a link to the Creative Commons licence, and indicate if changes were made. The images or other third party material in this article are included in the article's Creative Commons licence, unless indicated otherwise in a credit line to the material. If material is not included in the article's Creative Commons licence and your intended use is not permitted by statutory regulation or exceeds the permitted use, you will need to obtain permission directly from the copyright holder. To view a copy of this licence, visit http://creativecommons.org/licenses/by/4.0/. The Creative Commons Public Domain Dedication waiver (http://creativecommons.org/publicdomain/zero/1.0/) applies to the data made available in this article, unless otherwise stated in a credit line to the data. 


\section{Background}

Retention in HIV care is essential and provides opportunities to monitor response to therapy, prevent associated complications, and deliver ancillary services [1]. Retention in HIV health care services is a critical precursor to antiretroviral therapy (ART) adherence and viral suppression [2]. To prevent considerable HIV related morbidity and mortality, all HIV-positive persons must be put on ART and should remain in care to achieve virologic suppression [3]. According to the UNAIDS 90-90-90 strategy, $90 \%$ of those enrolled into HIV care should be retained. However, this has not yet been achieved in many settings and sub-populations including adolescents and young adults $[4,5]$. Few HIV positive youths below 25 years are retained in care after initiation of ART [6-8]. The poor retention in HIV care could be due to social, structural or health-related factors such as stigma and discrimination, distance and transport to the health facility, poverty and unemployment, work/child care responsibilities, and social relations as major determinants of retention in HIV care [9]. A recent study by Izudi and colleagues [10] in Uganda found that approximately $70 \%$ of adolescents were non-retained in care at Katooke Health Center, mid-western Uganda. Poor retention in care has been associated with the duration on ART and adolescent age, with older adolescents (15-19 years) having poorer retention in HIV care compared to younger adolescents aged 10-14 years [11]. Yet, suboptimal retention in HIV care is associated with poor ART adherence and suboptimal virologic non-suppression which worsen health outcomes [12, 13]. This in turn leads to increased HIV associated morbidity and mortality, and poor quality of life [14].

Previous studies in low and middle-income countries have observed that factors influencing retention in care are similar to those that influence adherence to ART $[15,16]$. Factors associated with retention in HIV care have been categorized into individual, political, socioeconomic, stigma and discrimination, sociodemographic and health system factors [17]. In Zambia, a mixed study to examine barriers to retention in HIV care of HIV positive adolescents identified multiple factors including stigma and discrimination, poverty, disrespectful treatment from clinicians, their adolescent-specific responsibilities (e.g. school), and cultural beliefs and traditions about illness [18]. However, there is a paucity of information about factors associated with retention in HIV care services among youths aged 15-24 years residing in rural settings of low income countries. Therefore, we aimed to determine retention in HIV care and associated factors among HIV positive youths aged 15-24 years enrolled for HIV care in rural southwestern Uganda.

\section{Methods}

\section{Study design \& site}

We conducted a cross-sectional study at an HIV clinic at Kabuyanda Health Centre IV in Isingiro district from July 2020 to August 2020. The health facility is located $108 \mathrm{Km}$ south of Mbarara city. Kabuyanda HC IV is the only public health facility in the area that offers HIV care services. The adult HIV clinic operates 2 days a week (Wednesday and Thursday) for Antiretroviral Therapy (ART) refill appointments but the adolescent HIV clinic operates every last Thursday of the month. At Kabuyanda HC IV, clients are given review visits depending on their clinical status, where stable and virally suppressed individuals are reviewed every 90 days. Clients who are clinically unstable and those with unsuppressed viral loads have their review visits individualized in a range of 30-60 days. During the nationwide lockdown in Uganda (from March 2020 to July 2020), the health workers and clinic peer educators at the clinic took responsibility of delivering drugs to the clients' homes. The clinic serves about 1200 HIV clients of whom 112 are youths aged 15-24 years. Isingiro district was selected for this study due to its young population: $57.2 \%$ aged $0-17$ years and $17.3 \%$ aged $15-24$ years [19]. The study area is a rural community with households earning their livelihood through subsistence farming and cattle keeping.

\section{Study participants}

The study participants were youth aged 15-24 years living with HIV who were accessing care at Kabuyanda Health Centre IV. We included youths who had been in care at the facility for at least 1 year. The youth who were less than 1 year in care at the facility at the time of the study were excluded.

\section{Sample size}

For this study, we screened all youth attending the HIV clinic at Kabuyanda HC IV for eligibility. Therefore a sample size for this study was not calculated a priori.

\section{Sampling and data collection}

A list of potential participants was generated by the data clerks and the HIV counsellor at the facility contacted the participants by phone calls and referred them to the research team at the facility who assessed their eligibility to participate in the study. Those who met the inclusion criteria, study aims were explained to them in their local language and were given a chance to ask questions for clarification. All eligible participants gave written informed consent to participate in this study. Participants below 18 years assented and their caregivers provided written informed consent. A consecutive sample of youths aged 15-24 years who consented to participate in the study were recruited. 


\section{Study variables}

\section{Retention HIV in care}

Our primary outcome variable was retention in HIV care. According to the Uganda ministry of health, retention HIV in care is defined as the number of HIV positive persons with at least $1 \mathrm{HIV}$ clinic visit within 90 days [10]. Therefore, in this study to determine retention in HIV care within a 1-year period, we defined retention as having attended at least 4 visits in 12 months prior to this study with at least 1 visit each quarter. The 12 months were divided into four equal quarters with each quarter consisting 90 days. The number of visits in each quarter was recorded. We reviewed participants' medical charts of 12 months before the study and each medical chart was assigned a code to ensure confidentiality. The number of clinic visits was abstracted from each participant's medical chart.

\section{Socio-demographic and disease characteristics}

A well-designed interviewer-administered questionnaire was created ( $\mathrm{S} 1 \mathrm{Text}$ ) to explore factors that influence retention in HIV Care. The tool was designed to capture the socio-demographic information including; age, gender, occupation, marital status, duration on treatment, ART regimen, whether perinatally acquired HIV (this was a verbal report of whether one was perinatally acquired HIV or not) and HIV disclosure status.

\section{HIV Berger Stigma Scale}

HIV-related stigma for each participant was measured using the Berger HIV Stigma Scale [20], which is a validated and standardized measure of stigma experienced by people living with HIV. It contains 40 -items scored on a 4-point Likert-type scale (strongly disagree, disagree, agree, strongly agree) with total stigma scores ranging from 40 to 160 . The scale measures 4 stigma subscales; (1)personalized stigma (assessed by 18 items) measuring consequences of people knowing ones HIV status including rejection by others, loss of close friends, (2) disclosure concerns (assessed by 10 items) which measure the likelihood that one will tell others about their HIV diagnosis, (3) negative self-image (assessed by 13 items) assessing individual's feelings about themselves, (4) concern with public attitudes (assessed by 20 items) which measures participants' public's perceptions of attitudes towards persons living with HIV [20]. Higher scores indicate a greater level of agreement with each item, and the severity of stigma.

\section{Data collection}

The Interviewer administered questionnaire and the Berger stigma scale were administered in the same interview with each participant. The duration of the interview was approximately $35-45 \mathrm{~min}$. Interviews were conducted in a doctor's room at the health facility to ensure privacy and confidentiality of patients' information. Participants who required post-interview counselling were referred to the facility counsellor after the interview.

\section{Data management}

At the end of every interview, the questionnaires were reviewed for completeness. The research team ensured that patient charts were de-identified and reviewed only once. Filled questionnaires were kept in a lockable cupboard to ensure data safety. Data entry forms were prepared in Microsoft excel 2013 where data were entered in duplicate to avoid errors. Entered data was saved and stored on a password-protected computer that was only accessed by the research team members. A copy of the same data set file was saved on a Flash disk stored by the principal investigator, as a back-up file. After data cleaning, data were exported to Stata version 15 (Statacorp, College Station, TX, USA) for analysis.

\section{Data analysis}

Descriptive statistics for categorical variables were presented in frequency tables while continuous variables were described using means and standard deviations. Retention in HIV care was calculated as the proportion of youths aged 15-24 years who sought care from Kabuyanda HC IV at least once each quarter in the 12 months prior to the study out of the total number of participants. The age of participants was stratified into adolescents (15-19years) and young adults (20-24 years). The total Berger stigma scale score and subscores of individual forms of stigma were obtained by adding Likert scores for individual items in the scale. Due to the lack of a universally accepted cut point of the scores, we adopted the categorization put forward by Charles and colleagues [21] in which the overall stigma scores were categorized into three categories as no/mild, moderate, and severe stigma using the 33rd and 66th percentile cut off values from the distribution of scores. From this, we obtained proportions of youths experiencing different levels of stigma. Considering the possible stigma scores for total stigma and the categories, participants who scored below the 33rd percentile of the stigma scale, were considered having no/mild stigma, those scored between 33rd and 66th percentile had Moderate stigma, and those above whose scores are above the 66th percentile had severe stigma. The proportion of participants with stigma was calculated as the total participants with moderate or severe stigma out of the total number of participants. The proportion of participants with different dimensions of stigma was calculated as the total participants with moderate or severe specific stigma dimension out of the total number of participants. 
At bivariate analysis, we analyzed categorical variables using cross-tabulations, crude odds Ratios (cOR) and a chi-square test to assess for the association between the participant characteristics (age, gender, occupation, marital status, geographical location, and disclosure status), HIV related stigma and the likelihood of retention in HIV care. All variables with a $P$ value $<0.2$, biological plausibility (age, level of education, HIV status disclosure and the four stigma subscales which were; personalized, disclosure concerns, negative self-image, and public attitudes) based on previous literature were considered for the multivariable logistic regression model. We performed a stepwise and backward selection procedure to determine the final parsimonious model of the independent factors associated with our outcome of interest. Confounding and interaction were assessed and the final model checked for goodness of fit using the Hosmer
Lemeshow test. The Adjusted Odds Ratios (AOR) with their corresponding $95 \%$ confidence interval were presented. A $P$ value $\leq 0.05$ was considered statistically significant.

\section{Results}

Socio-demographics and disease characteristics

The clinic consisted of a total of 112 youths aged 15-24 years in HIV care. Of these, 10 participants had been in HIV care for less than 12 months and were excluded from the study. We therefore enrolled a total of 102 participants in our study. The proportion of youth who were retained in HIV care over a 12 months period was $65.7 \%$. Of the participants who were enrolled into the study, the mean age was $20.95(\mathrm{SD} \pm 3.07)$ ranging from 15 to 24 years. The majority of the participants (77.5\%) were female, $74.5 \%$ aged $20-24$ years, and $69 \%$ had attained primary level of education as shown in Table 1.

Table 1 Socio-demographic and clinical characteristics of Youths aged 15-24 years receiving ART Care (N-102)

\begin{tabular}{|c|c|c|c|c|c|}
\hline \multirow[t]{2}{*}{ Characteristics } & \multirow[t]{2}{*}{ Categories } & \multirow[t]{2}{*}{ n (\%) } & \multicolumn{2}{|c|}{ Retention in HIV care } & \multirow[t]{2}{*}{$P$-value } \\
\hline & & & Yes n (\%) & No $n(\%)$ & \\
\hline \multirow[t]{2}{*}{ Age (years) } & 15-19 years & $26(25.5)$ & 18 (69.2) & $8(30.8)$ & 0.66 \\
\hline & $20-24$ years & $76(74.5)$ & $49(64.5)$ & $27(35.5)$ & \\
\hline \multirow[t]{2}{*}{ Sex } & Female & $79(77.5)$ & $47(59.5)$ & $32(40.5)$ & 0.01 \\
\hline & Male & $23(22.5)$ & $20(87.0)$ & $3(13.0)$ & \\
\hline \multirow[t]{2}{*}{ Marital status } & Married & $37(36.3)$ & $28(75.7)$ & $9(24.3)$ & 0.11 \\
\hline & Unmarried & $65(63.7)$ & $39(60.0)$ & $26(40.0)$ & \\
\hline \multirow[t]{3}{*}{ Level of education } & None & $17(16.7)$ & $11(64.7)$ & $6(35.3)$ & 0.99 \\
\hline & Primary & $71(69.6)$ & $47(66.2)$ & $24(33.8)$ & \\
\hline & Secondary & $14(13.7)$ & $9(64.3)$ & $5(35.7)$ & \\
\hline \multirow[t]{4}{*}{ Geographical location } & Kabuyanda SC & $49(48.0)$ & $33(67.3)$ & $16(32.7)$ & 0.49 \\
\hline & Kabuyanda TC & $15(14.7)$ & $12(80.0)$ & $3(20.0)$ & \\
\hline & Kikagati SC & $26(25.5)$ & $15(57.7)$ & $11(42.3)$ & \\
\hline & Other & $12(11.8)$ & $7(58.3)$ & $5(41.7)$ & \\
\hline \multirow[t]{2}{*}{ HIV status Disclosure } & No & $17(16.7)$ & $9(52.9)$ & $8(47.1)$ & 0.23 \\
\hline & Yes & $85(83.3)$ & $58(68.2)$ & $27(31.8)$ & \\
\hline \multirow[t]{2}{*}{ Perinatally acquired HIV } & Yes & 19 (18.6) & $17(89.5)$ & $2(10.5)$ & 0.02 \\
\hline & No & $83(81.4)$ & $50(60.2)$ & $33(39.8)$ & \\
\hline \multirow[t]{2}{*}{ Total stigma score } & Mild/Moderate & $42(41.2)$ & $29(68.3)$ & $13(31.7)$ & 0.14 \\
\hline & Severe & $60(58.8)$ & $38(63.3)$ & $22(36.7)$ & \\
\hline \multirow[t]{2}{*}{ Personalized stigma } & Mild/Moderate & $50(49.1)$ & $30(60.0)$ & $20(40.0)$ & 0.24 \\
\hline & Severe & $52(51)$ & $37(71.2)$ & $15(28.8)$ & \\
\hline \multirow[t]{2}{*}{ Disclosure concerns } & Moderate & $29(28.4)$ & $20(69.0)$ & $9(31.0)$ & 0.66 \\
\hline & Severe & $73(71.6)$ & $47(64.4)$ & 26(35.6) & \\
\hline \multirow[t]{2}{*}{ Negative self-image } & Moderate & $53(52)$ & $36(67.9)$ & $17(32.1)$ & 0.62 \\
\hline & Severe & $49(48)$ & $31(63.3)$ & 18(36.7) & \\
\hline \multirow[t]{2}{*}{ Public attitudes } & Moderate & $38(37.3)$ & $24(63.2)$ & $14(36.8)$ & 0.68 \\
\hline & Severe & $64(62.7)$ & $43(67.2)$ & 21(32.8) & \\
\hline
\end{tabular}




\section{Level of HIV related stigma}

The overall stigma scores ranged from 41 to 154 with a mean score of $112.25 \pm 21.77$ (95\% CI: 107.92, 116.48). The mean scores for the 4 stigma subscales were; personalized (49.03 \pm 10.39$)$, disclosure concerns (29.71 \pm $5.53)$, negative self-image ( $34.60 \pm 7.01)$, and public attitudes $(56.60 \pm 11.15)$. According to total stigma scores, $58.8 \%$ were severely stigmatized where as $41.2 \%$ experienced mild to moderate HIV related stigma. Majority of the participants experienced severe forms of stigma related to disclosure concerns (71.6\%) but comparatively lower for negative self-image (48\%).

In adjusted analyses, being male (aOR: $5.52,95 \% \mathrm{CI}$ $1.28,23.82, p<0.02$ ), married (aOR: $3.97,95 \%$ CI 1.42 , 11.13, $p<0.01$ ) and those who perinatally acquired HIV (aOR: $7.23,95 \%$ CI 1.16, 45.07, $p<0.03$ ) were independently associated with retention in HIV care as shown in Table 2.

\section{Discussion}

This study aimed to determine retention in HIV care and associated factors among youths aged 15-24 years enrolled at Kabuyanda HC IV in Isingiro district, southwestern Uganda. We found that retention in HIV care was $65.7 \%$. Youth who were male, married and had perinatally acquired HIV were significantly associated with retention in HIV care. HIV related stigma was not statistically significantly associated with retention in HIV care among our participants.

The level of retention in HIV care in our study is much lower than the UNAIDS target of 90\%, but similar to that reported in other studies done in Uganda by Okoboi et al. [22], who found a rate of $65 \%$ among Ugandan adolescents aged 10-19 years. However, the retention in HIV care rate of $65.7 \%$ in our study is much higher than $29.3 \%$ that was reported by Izudi et al. [10] in central Uganda.

Our findings on retention in HIV care are lower than those reported by Nabukeera et al. [23] in their study to establish adherence to antiretroviral therapy and retention in HIV care for adolescents living with HIV from 10 districts in Uganda who reported a retention in HIV care rate of $90 \%$. The difference may be due to differences in the characteristics of the study sample. While the study by Nabukeera et al. [23] recruited adolescents only (1019 years), we recruited both adolescents (15-19 years) and young adults (20-24 years). The retention in HIV care rate in our study is also lower than that of Brown

Table 2 Bivariate and Multivariate regression analysis of factors associated with retention in HIV care of youths aged 15-24 years $(N=102)$

\begin{tabular}{|c|c|c|c|c|c|c|c|}
\hline \multirow[t]{2}{*}{ Characteristics } & \multirow[t]{2}{*}{ Categories } & \multicolumn{2}{|c|}{ Retention in HIV care } & \multirow{2}{*}{$\begin{array}{l}\text { Crude Odds } \\
\text { Ratio }(95 \% \mathrm{Cl})\end{array}$} & \multirow[t]{2}{*}{$P$ value } & \multirow{2}{*}{$\begin{array}{l}\text { Adjusted Odds } \\
\text { Ratio }(95 \% \mathrm{Cl})\end{array}$} & \multirow[t]{2}{*}{$P$ value } \\
\hline & & Yes n (\%) & No $n(\%)$ & & & & \\
\hline \multirow[t]{2}{*}{ Age (years) } & $15-19$ years & $18(69.2)$ & $8(30.8)$ & ref & & ref & \\
\hline & 20-24 years & $49(64.5)$ & $27(35.5)$ & $0.81(0.31,2.10)$ & 0.66 & $1.78(0.47,6.80)$ & 0.40 \\
\hline \multirow[t]{2}{*}{ Sex } & Female & $47(59.5)$ & $32(40.5)$ & ref & & ref & \\
\hline & Male & $20(87.0)$ & $3(13.0)$ & $4.54(1.24,16.55)$ & 0.02 & $5.52(1.28,23.82)$ & 0.02 \\
\hline \multirow[t]{2}{*}{ Marital status } & Unmarried & $39(60.0)$ & $26(40.0)$ & ref & & ref & \\
\hline & Married & $28(75.7)$ & $9(24.3)$ & $2.07(0.84,5.10)$ & 0.11 & $3.97(1.42,11.13)$ & 0.01 \\
\hline \multirow[t]{3}{*}{ Level of Education } & None & $11(64.7)$ & $6(35.3)$ & ref & & & \\
\hline & Primary & $47(66.2)$ & $24(33.8)$ & $1.07(0.35,3.24)$ & 0.91 & & \\
\hline & Secondary & $9(64.3)$ & $5(35.7)$ & $0.98(0.22,4.30)$ & 0.98 & & \\
\hline \multirow[t]{2}{*}{ Perinatally acquired HIV } & No & $50(60.2)$ & $33(39.8)$ & ref & & ref & \\
\hline & Yes & $17(89.5)$ & $2(10.5)$ & $5.61(1.22,25.89)$ & 0.03 & $7.23(1.16,45.07)$ & 0.03 \\
\hline \multirow[t]{2}{*}{ Personalized stigma } & Mild/Moderate & $30(60.0)$ & $20(40.0)$ & ref & & & \\
\hline & Severe & $37(71.2)$ & $15(28.8)$ & $1.64(0.72,3.75)$ & 0.24 & & \\
\hline \multirow[t]{2}{*}{ HIV status disclosure } & No & $9(52.9)$ & $8(47.1)$ & ref & & ref & \\
\hline & Yes & $58(68.2)$ & $27(31.8)$ & $1.91(0.66,5.49)$ & 0.23 & $2.06(0.64,6.66)$ & 0.22 \\
\hline \multirow[t]{2}{*}{ Disclosure concerns } & Moderate & $20(69.0)$ & $9(31.0)$ & ref & & & \\
\hline & Severe & $47(64.4)$ & $26(35.6)$ & $0.81(0.32,2.04)$ & 0.66 & & \\
\hline \multirow[t]{2}{*}{ Negative self-image } & Moderate & $36(67.9)$ & $17(32.1)$ & ref & & & \\
\hline & Severe & $31(63.3)$ & 18(36.7) & $0.81(0.36,1.84)$ & 0.62 & & \\
\hline \multirow[t]{2}{*}{ Public attitudes } & Moderate & $24(63.2)$ & 14(36.8) & ref & & & \\
\hline & Severe & $43(67.2)$ & $21(32.8)$ & $1.19(0.52,2.77)$ & 0.68 & & \\
\hline
\end{tabular}


et al. [24] among youths 15-24 years in rural Kenya where $81 \%$ of these youths had been retained in HIV care at 1 year.

Youths who were married were significantly associated with retention in HIV care in our study. Our findings are similar to those reported by Umeokonkwo et al. [25] in Anambra state in Nigeria in which marital status was a significant predictor of retention in HIV care. Being married, or having a spouse provides a source of psychological and emotional support which improves retention in HIV care compared to those who are single and not in a relationship. In a study by Santos et al. [26] to determine the source of social support of people with HIV, the main source of physical, emotional and social support were spouses/partners. However, a study about predictors of retention in HIV care among youth (15-24 years) in a universal test-and-treat setting in rural Kenya, didn't find any association between marital status and retention in HIV care [24].

Youth who perinatally acquired HIV are likely to be retained in HIV care. In a study in United Kingdom, among young adults with perinatally acquired HIV infection that assessed the clinical outcomes post transition to adult services, $86 \%$ of these youths were retained in HIV care [27]. In a systematic review by Ritchwood et al. [28] to examine retention in HIV care, it indicated that more than $70 \%$ of such adolescents who were infected with HIV perinatally were retained in care 1-2 years post-Health Care Transition. Such youths are better retained in care because of the special attention they receive during their paediatric HIV care, and the intense preparations for transitions into adult care [29]. These adolescents and young adults have been found to have a special patient-provider relationship that is constituted by a strong bond in between since the provider understands the patient in details [29]. There is an element of adaptation to the clinic environment, boosted by the individual experience [28].

In this study, males show a more likelihood of being retained in HIV care. This finding is similar to that reported by Valverde et al. [30], that showed that retention in care rates were lower for females than for males. This finding deviates from commonest findings from many studies that have been done, that instead show a female predilection of good retention in HIV care [31-33]. This improvement in male retention may be a result of the many interventions, modifications in care and recommendations of male involvement in elimination of mother to child transmission (eMTCT) services in Uganda [34, 35]. This integrated practice in Uganda reinforces, HIV treatment support, economic support and psychosocial support among the expectant couple [35]. Such services have been shown to improve male involvement, and hence indirectly impacting positively on their retention in HIV care.
Our study did not find an association between HIV related stigma and retention in HIV care. This is similar to what was found in other studies [36-38]. However, there are studies which showed that HIV related stigma was associated with retention in HIV care [39-45]. This may be because of differences in study designs as some of the studies were qualitative studies $[44,45]$. These studies [39-42] were also carried out in a different setting compared to ours, with varying tools to measure HIV related stigma as well as varying age groups. This suggests that there may be geographic, cultural and age differences between these studies and our study. The difference in our findings could also be due to our strict definition of retention as some studies that found an association between HIV related stigma and retention in care have defined poor retention as going 12 months since the last documented clinic visit [43]. Some authors have also suggested that HIV related stigma may hinder initial linkage to care but play a lesser role on retention of patients in care [36]. This may explain the lack of association between HIV related stigma and retention in care for those already linked to care.

\section{Limitations}

This study has some limitations. The Berger Stigma Scale used to assess stigma has commonly been used in the adult population. In Uganda, an adult is any person $\geq 18$ years of age. However, in this study we had some participants aged below 18 years who were subjected to the same tool to assess stigma. The definition of retention that was used in this study was conservative and might potentially have underestimated the true retention of youths in care. In this study, we were not able to assess the association between retention and factors such as immunological/virologic status (CD4 count and HIV viral load measures) or ART duration, poverty/income. Perinatally acquired HIV was only assessed verbally. Finally, this study only employed a quantitative approach and therefore we did not collect information on patient's reasons for not attending scheduled visits.

\section{Conclusion}

Youths aged 15-24 years are still poorly retained in HIV care in rural southwestern Uganda despite the efforts put in place by the ministry of health to improve HIV care. Being male, having perinatally acquired HIV and married or in a relationship are associated with retention in HIV care.

\section{Recommendations}

We recommend interventions specifically targeting adolescents and young adults living with HIV to improve retention in HIV care especially in rural settings. These interventions should focus on improving social and 
emotional support through the creation and enhancement of peer support projects and friendly services to optimize retention in HIV care for adolescents and young adults (15-24 years) who live with HIV in rural Uganda. There is need for further research studies to qualitatively identify the barriers and facilitators to retention of adolescents and young adults in HIV care services.

\section{Abbreviations}

ART: Antiretroviral therapy; HC IV: Health Centre Four (IV); HIV: Human Immunodeficiency Virus; UBOS: Uganda Bureau of Statistics

\section{Supplementary Information}

The online version contains supplementary material available at https://doi. org/10.1186/s12889-021-11547-5.

\section{Additional file 1}

\section{Acknowledgements}

We acknowledge the District Health Officer and Kabuyanda HC IV facility incharge for the ethical approvals to collect data from the facility. We also appreciate the HIV Clinic team of the facility for their support during the data collection phase of the study. We also thank the study participants who willingly entrusted us with their valued information. We express gratitude and appreciation to the management of Mbarara University of Science and Technology and the HEPI-TUITAH Program management that made immense contributions and technical support to the success of this study.

\section{Authors' contributions}

LAP conceived the idea, supervised concept writing, and protocol writing. AKS participated in concept development and protocol writing. KV participated in concept development and writing, protocol writing, and data collection. SE participated in concept development and writing, protocol writing, translation of study tools, data collection, review and editing of the original manuscript draft. AE participated in concept development and writing, protocol writing and translation of study tools. MM participated in concept development and writing, protocol writing, supervised data collection and analysis, developed the first draft of the manuscript, review and editing the original manuscript draft. HML and GZR mentored the team and participated in writing, reviewing and editing the manuscript draft. SA contributed to the review and revision of the manuscript. All authors reviewed and approved the final manuscript for publication.

\section{Funding}

Research reported in this publication was supported by the Fogarty International Center (U.S. Department of State's Office of the U.S. Global AIDS Coordinator and Health Diplomacy (S/GAC) and the President's Emergency Plan for AIDS Relief (PEPFAR) of the National Institutes of Health under Award Number R25TW011210. The content is solely the responsibility of the authors and does not necessarily represent the official views of the National Institutes of Health. The funding bodies played no role in the design of the study and collection, analysis, and interpretation of data and in writing the manuscript.

\section{Availability of data and materials}

All the data needed for this manuscript has been included. In case there is a need for clarifications, the corresponding author can be contacted.

\section{Declarations}

\section{Ethics approval and consent to participate}

The study was reviewed and approved by the Research Ethics Committee of Mbarara University of Science and Technology (MUST REC 20/01-20). The Uganda National Council of Science and Technology (UNCST) gave the regulatory clearance to conduct the study in Uganda (RESCLEAR/01). Administrative clearance to carry out the study at the facility was granted by the District Health Officer of Isingiro district, and the In-Charge of Kabuyanda HC IV. Unique identification participant codes were used to identify participants hence, no participant identifiers were captured at data entry to ensure their privacy and confidentiality. Written informed consent was obtained from all participants as well as verbal assent for participants aged $<18$ for whom the caretakers provided written consent.

\section{Consent for publication}

Not applicable.

\section{Competing interests}

The authors have no competing interests.

\section{Author details}

${ }^{1}$ Mbarara University of Science and Technology, Faculty of Medicine, Mbarara, Uganda. ${ }^{2}$ Department of Obstetrics and Gynecology, Mbarara University of Science and Technology, Mbarara, Uganda. ${ }^{3}$ Department of Psychiatry, Mbarara University of Science and Technology, Mbarara, Uganda.

Received: 1 October 2020 Accepted: 23 July 2021

Published online: 31 July 2021

\section{References}

1. Vithalani J, Herreros-Villanueva M. HIV epidemiology in Uganda: survey based on age, gender, number of sexual partners and frequency of testing. Afr Health Sci. 2018;18(3):523-30. https://doi.org/10.4314/ahs.v18i3.8.

2. Stricker SM, Fox KA, Baggaley R, Negussie E, de Pee S, Grede N, et al. Retention in care and adherence to ART are critical elements of HIV care interventions. AIDS Behav. 2014;18(Suppl 5):S465-75.

3. Kempf MC, McLeod J, Boehme AK, Walcott MW, Wright L, Seal P, et al. A qualitative study of the barriers and facilitators to retention-in-care among HIV-positive women in the rural southeastern United States: implications for targeted interventions. AIDS Patient Care STDs. 2010;24(8):515-20. https:// doi.org/10.1089/apc.2010.0065

4. Farmer C, Yehia BR, Fleishman JA, Rutstein R, Mathews WC, Nijhawan A, et al. Factors associated with retention among non-perinatally HIV-infected youth in the HIV research network. J Pediatric Infect Dis Soc. 2016;5(1):3946. https://doi.org/10.1093/jpids/piu102.

5. Janssen S, Wieten RW, Stolp S, Cremers AL, Rossatanga EG, KlipsteinGrobusch K, et al. Factors associated with retention to care in an HIV clinic in Gabon, Central Africa. PLoS One. 2015;10(10):e0140746. https://doi.org/1 0.1371/journal.pone.0140746

6. Eduardo E, Lamb MR, Kandula S, Howard A, Mugisha V, Kimanga D, et al. Characteristics and outcomes among older HIV-positive adults enrolled in HIV programs in four sub-Saharan African countries. PLoS One. 2014:9(7): e103864. https://doi.org/10.1371/journal.pone.0103864.

7. Lamb MR, Fayorsey R, Nuwagaba-Biribonwoha H, Viola V, Mutabazi V, Alwar T, et al. High attrition before and after ART initiation among youth (15-24 years of age) enrolled in HIV care. AIDS. 2014;28(4):559-68. https://doi.org/1 0.1097/QAD.0000000000000054.

8. Zanoni BC, Mayer KH. The adolescent and young adult HIV cascade of care in the United States: exaggerated health disparities. AIDS Patient Care STDs. 2014;28(3):128-35. https://doi.org/10.1089/apc.2013.0345.

9. Geng EH, Bangsberg DR, Musinguzi N, Emenyonu N, Bwana MB, Yiannoutsos CT, et al. Understanding reasons for and outcomes of patients lost to follow-up in antiretroviral therapy programs in Africa through a sampling-based approach. J Acquir Immune Defic Syndr. 2010;53(3):405-11. https://doi.org/10.1097/QAl.0b013e3181b843f0.

10. Izudi J, Mugenyi J, Mugabekazi M, Muwanika B, Tumukunde Spector V, Katawera A, et al. Retention of HIV-positive adolescents in care: a quality improvement intervention in mid-western Uganda. Biomed Res Int. 2018; 2018:1-8. https://doi.org/10.1155/2018/1524016.

11. Atuyambe LM, Ssegujja E, Ssali S, Tumwine C, Nekesa N, Nannungi A, et al. HIV/AIDS status disclosure increases support, behavioural change and, HIV prevention in the long term: a case for an Urban Clinic, Kampala, Uganda. BMC Health Serv Res. 2014;14:276.

12. Kakkar F, Van der Linden D, Valois S, Maurice F, Onnorouille M, Lapointe N, et al. Health outcomes and the transition experience of HIV-infected adolescents after transfer to adult care in Quebec, Canada. BMC Pediatr. 2016;16(1):109. https://doi.org/10.1186/s12887-016-0644-4. 
13. Auld AF, Agolory SG, Shiraishi RW, Wabwire-Mangen F, Kwesigabo G, Mulenga $\mathrm{M}$, et al. Antiretroviral therapy enrollment characteristics and outcomes among HIV-infected adolescents and young adults compared with older adults-seven African countries, 2004-2013. MMWR Morb Mortal Wkly Rep. 2014;63(47):1097-103.

14. UNAIDS. Global AIDS update 2018. State of the epidemic. Geneva: UNAIDS; 2018. p. 376

15. Azia IN, Mukumbang FC, van Wyk B. Barriers to adherence to antiretroviral treatment in a regional hospital in Vredenburg, Western cape, South Africa. South Afr J HIV Med. 2016;17(1):476. https://doi.org/10.4102/sajhivmed.v17i1.476.

16. MacDonell K, Naar-King S, Huszti H, Belzer M. Barriers to medication adherence in behaviorally and perinatally infected youth living with HIV. AIDS Behav. 2013;17(1):86-93. https://doi.org/10.1007/s10461-012-0364-1.

17. Kenneth Mugisha AO, Semafumu E, Ciccio L, Muwanika RF, Otim J, Makumbi M. Retention of HIV positive persons in antiretroviral therapy programs in post-conflict northern uganda-baseline survey of 17 health units; 2009.

18. Mesic A, Halim N, MacLeod W, Haker C, Mwansa M, Biemba G. Facilitators and barriers to adherence to antiretroviral therapy and retention in care among adolescents living with HIV/AIDS in Zambia: a mixed methods study. AIDS Behav. 2019;23(9):2618-28. https://doi.org/10.1007/s10461-01902533-5.

19. Uganda Bureau of Statistics. The National Population and Housing Census 2014- Main Report, Kampala, Uganda; 2016.

20. Berger $B E$, Ferrans $C E$, Lashley FR. Measuring stigma in people with HIV: psychometric assessment of the HIV stigma scale. Res Nurs Health. 2001; 24(6):518-29. https://doi.org/10.1002/nur.10011.

21. Charles B, Jeyaseelan L, Pandian AK, Sam AE, Thenmozhi M, Jayaseelan V. Association between stigma, depression and quality of life of people living with HIV/AIDS (PLHA) in South India - a community based cross sectional study. BMC Public Health. 2012;12(1):463. https://doi.org/10.1186/1471-24 58-12-463.

22. Okoboi S, Ssali L, Yansaneh Al, Bakanda C, Birungi J, Nantume S, et al. Factors associated with long-term antiretroviral therapy attrition among adolescents in rural Uganda: a retrospective study. J Int AIDS Soc. 2016;19(5 Suppl 4):20841. https://doi.org/10.7448/IAS.19.5.20841.

23. Nabukeera-Barungi N, Elyanu P, Asire B, Katureebe C, Lukabwe I, Namusoke $E_{\text {, et }}$ al. Adherence to antiretroviral therapy and retention in care for adolescents living with HIV from 10 districts in Uganda. BMC Infect Dis. 2015;15(1):520. https://doi.org/10.1186/s12879-015-1265-5.

24. Brown LB, Ayieko J, Mwangwa F, Owaraganise A, Kwarisiima D, Jain V, et al. Predictors of retention in HIV care among youth (15-24) in a universal testand-treat setting in rural Kenya. J Acquir Immune Defic Syndr. 2017;76(1): e15-e8. https://doi.org/10.1097/QAl.0000000000001390.

25. Umeokonkwo CD, Onoka CA, Agu PA, Ossai EN, Balogun MS, Ogbonnaya LU. Retention in care and adherence to HIV and AIDS treatment in Anambra state Nigeria. BMC Infect Dis. 2019;19(1):654. https://doi.org/10.11 86/s12879-019-4293-8.

26. Santos VF, Pedrosa SC, Aquino PS, Lima ICV, Cunha GH, Galvão MTG. Socia support of people with HIV/AIDS: the social determinants of health model. Rev Bras Enferm. 2018;71(suppl 1):625-30. https://doi.org/10.1590/0034-71 67-2017-0346.

27. Foster C, Ayers S, McDonald S, Frize G, Chhabra S, Pasvol TJ, et al. Clinical outcomes post transition to adult services in young adults with perinatally acquired HIV infection: mortality, retention in care and viral suppression. AIDS. 2020;34(2):261-6. https://doi.org/10.1097/QAD.0000000000002410.

28. Ritchwood TD, Malo V, Jones C, Metzger IW, Atujuna M, Marcus R, et al. Healthcare retention and clinical outcomes among adolescents living with HIV after transition from pediatric to adult care: a systematic review. BMC Public Health. 2020;20(1):1195. https://doi.org/10.1186/s12889-020-09312-1.

29. Katusiime C, Schlech WF 3rd, Parkes-Ratanshi R, Sempa J, Kambugu A. Characteristics of sexually transmitted infections among high-risk HIVpositive patients attending an urban clinic in Uganda. J Int Assoc Provid AIDS Care. 2016;15(1):36-41. https://doi.org/10.1177/2325957413506493.

30. Valverde E, Rodriguez A, White B, Guo Y, Waldrop-Valverde D. Understanding the Association of Internalized HIV Stigma with retention in HIV Care. J HIV AIDS. 2018;4(3). https://doi.org/10.16966/2380-5536.159.

31. Ochieng-Ooko V, Ochieng D, Sidle JE, Holdsworth M, Wools-Kaloustian K, Siika AM, et al. Influence of gender on loss to follow-up in a large HIV treatment programme in western Kenya. Bull World Health Organ. 2010; 88(9):681-8. https://doi.org/10.2471/BLT.09.064329.
32. Kebede HK, Mwanri L, Ward P, Gesesew HA. Predictors of lost to follow up from antiretroviral therapy among adults in sub-Saharan Africa: a systematic review and meta-analysis. Infect Dis Poverty. 2021;10(1):33. https://doi.org/1 0.1186/s40249-021-00822-7.

33. Koech E, Teasdale CA, Wang C, Fayorsey R, Alwar T, Mukui IN, et al. Characteristics and outcomes of HIV-infected youth and young adolescents enrolled in HIV care in Kenya. AIDS. 2014;28(18):2729-38. https://doi.org/10.1 097/QAD.0000000000000473.

34. Triulzi I, Palla I, Ciccacci F, Orlando S, Palombi L, Turchetti G. The effectiveness of interventions to involve men living with HIV positive pregnant women in low-income countries: a systematic review of the literature. BMC Health Serv Res. 2019;19(1):943. https://doi.org/10.1186/s12 913-019-4689-6.

35. Muwanguzi PA, Nassuna LK, Voss JG, Kigozi J, Muganzi A, Ngabirano TD, et al. Towards a definition of male partner involvement in the prevention of mother-to-child transmission of HIV in Uganda: a pragmatic grounded theory approach. BMC Health Serv Res. 2019;19(1):557. https://doi.org/10.11 86/s12913-019-4401-x

36. McCoy K, Lipira L, Kemp CG, Nevin PE, Huh D, Turan JM, et al. Exploring HIV-related stigma as a determinant of engagement in HIV care by African American women. J Assoc Nurses AIDS Care. 2020;31(2):167-75. https://doi. org/10.1097/JNC.0000000000000140.

37. Traeger L, O'cleirigh C, Skeer MR, Mayer KH, Safren SA. Risk factors for missed HIV primary care visits among men who have sex with men. Behav Med. 2012;35(5):548-56. https://doi.org/10.1007/s10865-011-9383-z.

38. Wohl AR, Galvan FH, Myers HF, Garland W, George S, Witt M, et al. Do social support, stress, disclosure and stigma influence retention in HIV care for Latino and African American men who have sex with men and women? AIDS Behav. 2011;15(6):1098-110. https://doi.org/10.1007/s10461-010-9833-6.

39. Christopoulos KA, Neilands TB, Hartogensis W, Geng EH, Sauceda J, Mugavero MJ, et al. Internalized HIV stigma is associated with concurrent viremia and poor retention in a cohort of US patients in HIV care. J Acquir Immune Defic Syndr (1999). 2019;82(2):116.

40. Logie CH, Lacombe-Duncan A, Wang Y, Kaida A, Conway T, Webster K, et al. Pathways from HIV-related stigma to antiretroviral therapy measures in the HIV care cascade for women living with HIV in Canada. J Acquir Immune Defic Syndr (1999). 2018;77(2):144.

41. Pantelic M, Casale M, Cluver L, Toska E, Moshabela M. Multiple forms of discrimination and internalized stigma compromise retention in HIV care among adolescents: findings from a south African cohort. J Int AIDS Soc. 2020;23(5):e25488. https://doi.org/10.1002/jia2.25488.

42. Rice WS, Burnham K, Mugavero MJ, Raper JL, Atkins GC, Turan B. Association between internalized HIV-related stigma and HIV care visit adherence. J Acquir Immune Defic Syndr (1999). 2017;76(5):482.

43. Valenzuela C, Ugarte-Gil C, Paz J, Echevarria J, Gotuzzo E, Vermund SH, et al. HIV stigma as a barrier to retention in HIV care at a general hospital in Lima, Peru: a case-control study. AIDS Behav. 2015;19(2):235-45. https://doi.org/1 0.1007/s10461-014-0908-7.

44. Yehia BR, Stewart L, Momplaisir F, Mody A, Holtzman CW, Jacobs LM, et al. Barriers and facilitators to patient retention in HIV care. BMC Infect Dis. 2015; 15(1):1-10.

45. Tomori C, Kennedy CE, Brahmbhatt H, Wagman JA, Mbwambo JK, Likindikoki S, et al. Barriers and facilitators of retention in HIV care and treatment services in Iringa, Tanzania: the importance of socioeconomic and sociocultural factors. AIDS Care. 2014;26(7):907-13. https://doi.org/10.1 080/09540121.2013.861574

\section{Publisher's Note}

Springer Nature remains neutral with regard to jurisdictional claims in published maps and institutional affiliations. 